\title{
The development of "Chok" local plant in kind of palm to "Jungsui" Creative dance uniform in Thailand
}

\author{
Sawit Pongvat ${ }^{1}$, Yuttapong Tonpradoo ${ }^{2}$, Jenasama Srihirun ${ }^{3}$ \\ ${ }^{1}$ Faculty of Humanities and Social Sciences, Phuket Rajabhat University, \\ ${ }^{2}$ Faculty of fine and Applied arts and cultural Sciences, Mahasarakham University, \\ ${ }^{3}$ Faculty of Business Administration and Accountancy, Khon Kaen University \\ 1'pkruphuket@gmail.com, ${ }^{2}$ yuttapong.t@msu.ac.th.com, ${ }^{3}$ jenasama.srihirun@gmail.com
}

\begin{abstract}
This research aimed to 1) study the history of "Chok" local plant in kind of palm 2) The development of the "Chok" local plant in kind of palm to Jungsui to creative dance uniform. This research was conducted by qualitative methods including data collection were documentary research, observation, in-depth interviews and two focus groups with stakeholders. Content analysis was applied to analyst the research. The finding shown that 1) The "Chok" was a local southern plant with a growth period of about $15-20$ years 2) Mining miners have created wisdom by bringing "Chok" local plant in kind of palm that it was not invented to "Jungsui" Creative dance uniform because it was resistant to wear to prevent rain. By discovering the steps of the invention of the seven steps. 3) Phang Nga province had a variety of local plants. However, Expanding tourism made the encroachment of natural areas. So., Local ecosystems and plants were destroyed. While, some local plants that were worthless. Beneficial of "Choke" was applied to create an economies at both micro and macro levels and able to maintain the inventive local Thai wisdom knowledge the "Jungsui" when applied to craftsmanship and creative costume.
\end{abstract}

Keywords

"Chok" local plant in kind of palm / Jungsui / Creative dance uniform

Article Received: 10 August 2020, Revised: 25 October 2020, Accepted: 18 November 2020

\section{Introduction}

Arenga Westerhoutti Griff or sugar palm is a local plant in the southern part of Thailand. It has the characteristics of palms. It grows on rock mountains. It takes about 20 years from the beginning growths of seeds to the trees bearing fruits. After bearing the fruits, the trees bloom and wilt. While the trees are wilting, the barks are useful. However, most gardeners let the tree wilt and rotten.

The Chinese people have immigrated to the southern part of Thailand since the reign of King Rama 3. It was because China had three major problems: 1) the cultural revolutions, 2 ) the corruptions, and 3 ) the famine resulting in the poverty. 1 The Chinese people combined the wisdom of the mining profession with the ways of lives. Importantly, the fibers of the sugar palm trees were the materials of Jungsui (i.e. rain coats) for mining. Presently, the rain coats are rare. If the rain coats are not conserved, then the wisdoms that have been inherited from generations to generations will be lost. Accordingly, the researcher acknowledged the benefits from using the barks in order to provide economic values and to promote the cultural tourism by producing the rain coats from the barks without the economic values and developing the rain coats in order to the costumes for creative dances by combining the ideas and invention processes in order to create different artworks and to innovate handicrafts for the tourism market.

The key of the study and applications of the development of the barks into the rain coats for the creative dances was the production of the rain coats with the local plants (i.e. sugar palm trees).

Since the mentioned information had never actually been collected by any scholar in any field for further applications, the researcher was interested in studying the main characteristics of the local plants in order to develop the barks into the rain coats for the creative dances.

\section{Research Objectives}

The objectives of this research article were 1)To develop the barks into the rain coats 2) To develop the rain costs into the costumes for the creative dances.

\section{Research Methods}

\section{A. Research Design}

In the research study, the development of the barks into the rain costs for the creative dances, the scope of the study was defined by the researcher as follows.

\section{Population and Samples}

1) Population and samples were selected with the purposive sampling method and divided into three groups as follows.

2) The key informants included an expert(s) with experiences and expertise in arts and cultures, wisdom teacher(s), personnel of Tourism Authority of Thailand (Phuket Provincial Office), and the head of the sugar tree planting group in Bang Toei Sub-District, Mueang District, Phang Nga Province.

3) The casual informants included the personnel of Tourism Authority of Thailand (Phuket Provincial Office) and the members of the sugar palm planting group in Bang Toei Sub-District, Muang District, Phang Nga Province. 
4) The general informants included the student of the performing arts program of Phuket Rajabhat University and the Phuket Women's Empowerment Fund.

\section{Research/Data Collection Sites}

Bang Toei Sub-District, Muang District, Phang Nga Province

\section{Research Instruments}

1) Relevant documents and research studies

2) Structured and unstructured interviews

3) Participatory and non-participatory observations

4) Small group meetings

5) Workshop

\section{Data collection}

This research study used the qualitative research method by collecting the data from the documents such as

1) the cultural and historical developments, identities, and wisdoms of Phang Nga Province (the history of the local plants or sugar palm trees were studied);

2) and the other cultural documents about the biodiversity and geography of the Andaman coast of the southern part and Phang Nga Province.

The field study consisted of the interviews as follows.

1) The unstructured interviews had the openendedquestions.

2) The structured Interviews comprised of three parts with following details.

Part 1 was the personal information about genders, status, educational background, primary occupation, monthly income and other information.

Part 2 included the main questions about the history of the local plants (i.e. sugar palm trees) in Phang Nga Province.

3) The in-depth interviews were unstructured interviews for interviewing the key informants and casual informants regarding the history of the local plants (i.e. sugar palm trees) in Phang Nga Province and the changes of the social contexts affecting the cultivation and fertility of the local plants.

4) The observations consisted of the followings.

4.1) The participant observations were such as participating in the local plantation activities in Phang Nga Province.

4.2) The non-participant observations included observing the general conditions of the research site by the researcher. The researcher studied the ways of lives and various local wisdoms according to research objectives.

5. The focused group was formed by the researcher in order to collect data from the educators and practitioners sharing their opinions, analyzing problems analysis, and providing suggestions for the study, the development of the barks into the rain costs for the creative dances. The conversation plans, date, time, place, questions, appointments, and invitations were prepared by the homogenous group members.

\section{Results}

Results indicated that

\section{The Results of the Development of the Sugar Palm Barks into the Rain Coats}

The Chinese mining workers created the wisdoms by developing the barks of the local plants that were valueless into the raincoats because the rain coats were durable for mining. The fibers of the barks of the palm trunks were called "Rok Chok" by the villagers and used for creating the rain coats that were found in the mines in Kathu District. These are the wisdoms inherited from generations to generations. The rain coats are kept at Wat Pra Thong, Thalang District, Phuket Province.

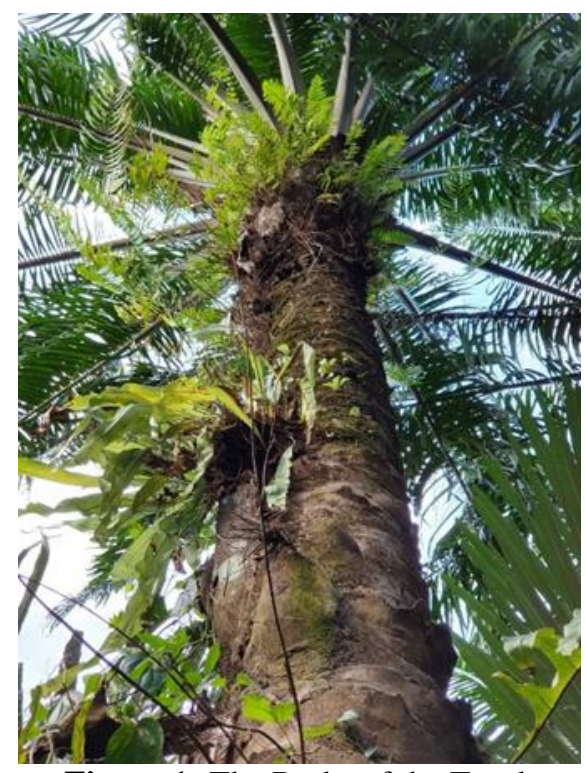

Figure 1: The Barks of the Trunk

Source: Yuttapong Tonpradoo (on 15th February 2018)

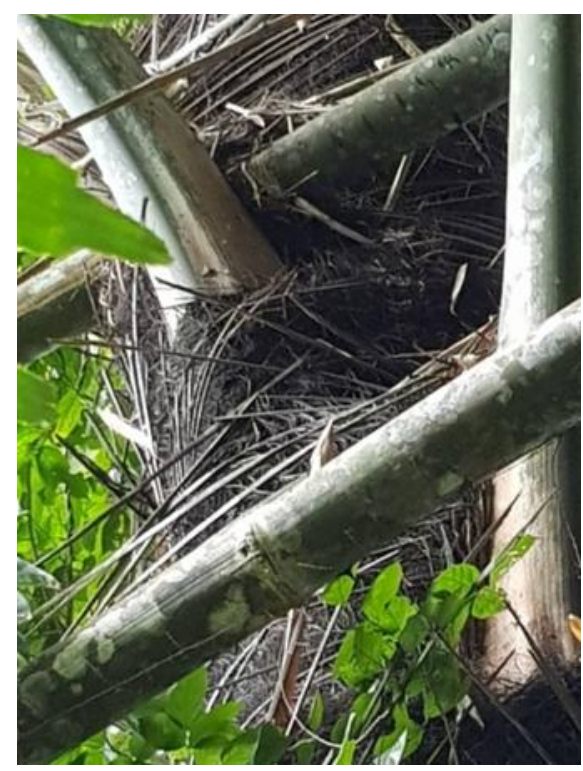

Figure 2: The Barks of the Trunk

Source: Yuttapong Tonpradoo (on 15th February 2018)

The Seven Production Steps of the Rain Coats

1) Take the stems out of the barks.

2) Soak the barks in the salt water in order to make the barks thicker and stickier, and then completely sun-dry the barks. 
3) Align the completely sun-dried barks on the same floor.

4) Cut the barks according to the plans.

5) Backstitch the barks with needles and threads.

6) Bind the barks with ropes in order to produce the durable rain coats.

7) Sew the prepared buttons on the rain coats.

Then, the production steps were used by the researcher as the guidelines for developing the rain coats for the creative dances.

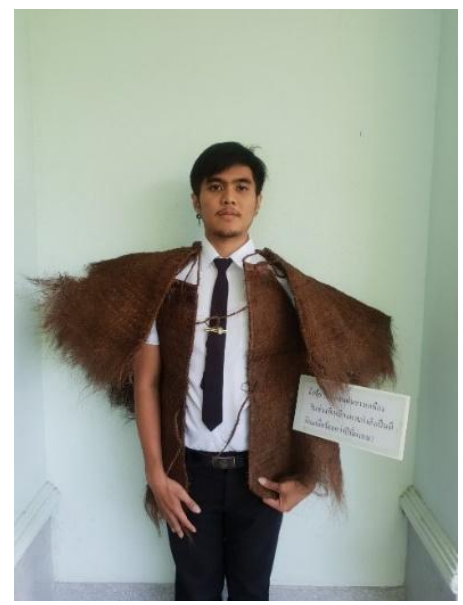

Figure 3: The Rain Coat

Source: Yuttapong Tonpradoo(on 2nd April 2018)

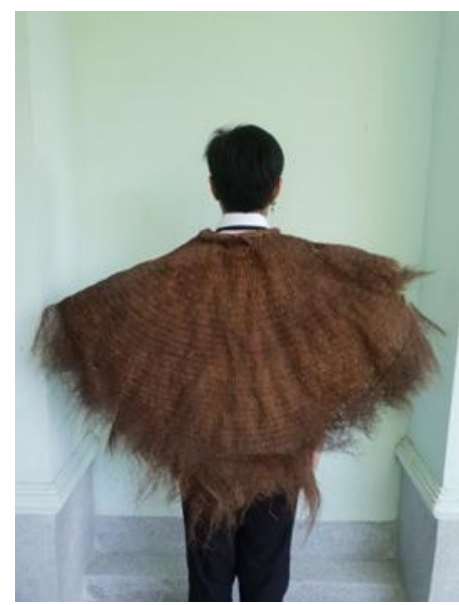

Figure 4: The Rain Coat

Source: Yuttapong Tonpradoo(on 2nd April 2018)

\section{The Results of the Development of the Rain Coats for the Creative Dances}

The applications of the sugar palm barks for the creative dances were not studied and publicized systematically, and the local philosophers were old. Consequently, the mentioned wisdoms may be lost. According to the results, the rain coats that were suitable for men and women were produced by the researcher The results can be applied by the public, private and civil society sectors at the 1) policy level and 2) the micro and macroeconomic levels in order to create the main identities of communities for sustainable economic development and to adapt the rain coats to the changing social contexts. Regarding the applications of the creative dances, the ways of the lives of the mining workers were applied by the research to the creative dances as suggested by the experts.

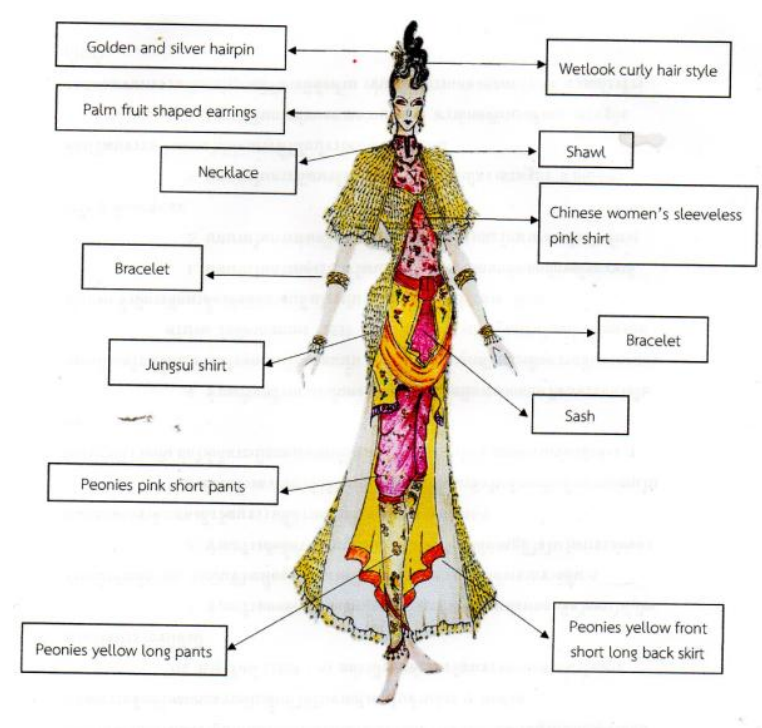

Figure 5: The Researcher and Colleagues' Creative Costumes of Female Dancers
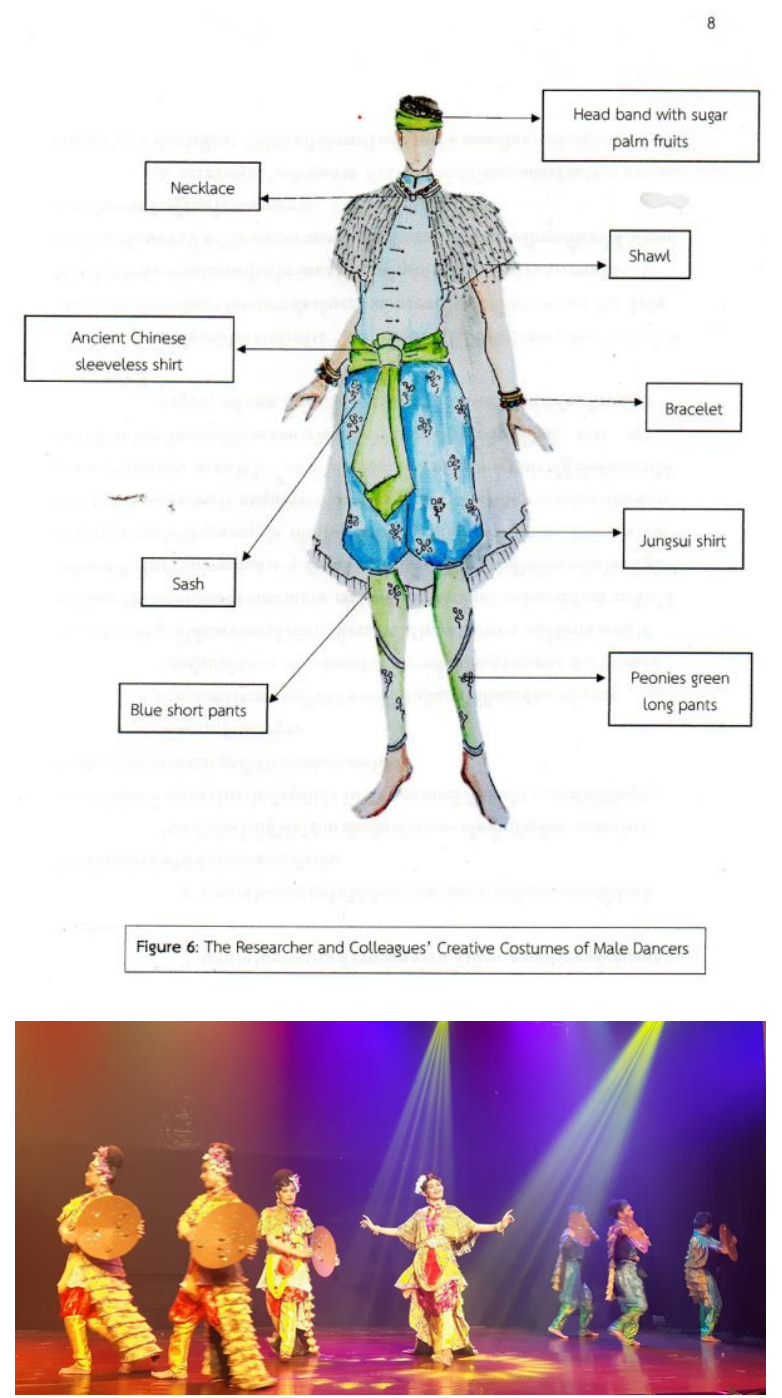

Figure 7: Creative Dance 1

Source: Yuttapong Tonpradoo (on 18th November 2019) 


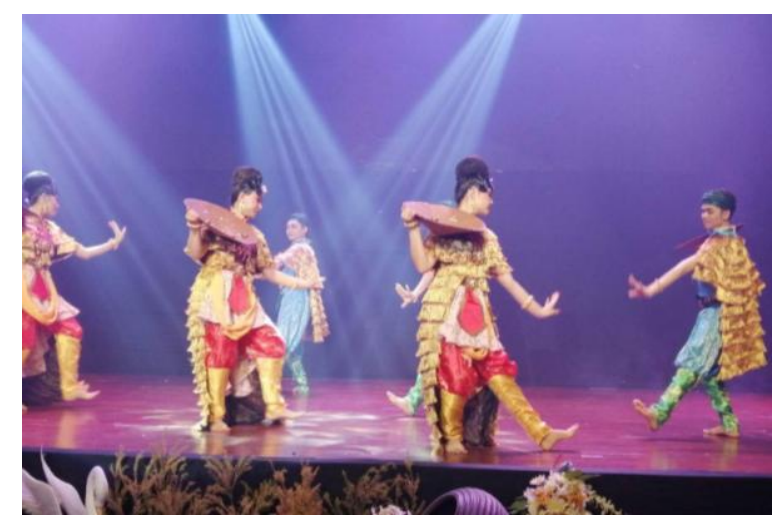

Figure 8: Creative Dance 2

Source: Yuttapong Tonpradoo (on 18th November 2019)

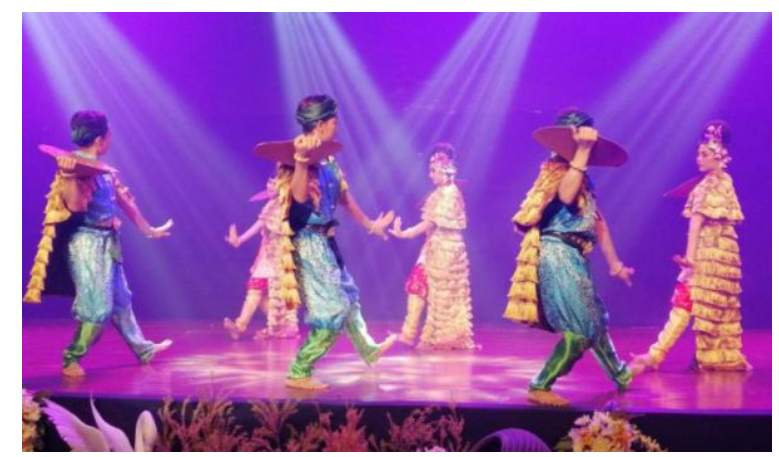

Figure 9: Creative Dance 3

Source: Yuttapong Tonpradoo (on 18th November 2019)

\section{Discussions}

The results from the workshop with the Key and Casual Groups provided the following suggestions. After conducting the study, the knowledge was transferred to the organizations about Phuket's cultures and educational institutes. The knowledge should be transferred to the public in order to promote the identities of Phang Nga Province and locally economic groups in order to produce souvenirs for generating household incomes. The knowledge had the following significances: 1) learning the diversity of the local plants indicating the geographical characteristics Of Phang Nga Province, 2) reducing the problems of product design plagiarism, and 3) using the local materials for designing the costumes in order to provide the jobs for the local people, to sustainably develop the economy, and educate tourists about the prides and identities of the local communities as well as make the local people value the benefits of the local plants. The results were novel. These can be the knowledge and applications to handicrafts in order to promote the tourism of Phang Nga Province.

\section{Recommendations}

\section{A. Recommendations for Practices}

The results from the workshop is Key and Casual Group give feedback as follows: After conducting research Researchers should transfer the knowledge gained to Phang Nga culture, Related agencies, educational institutes and It should be publicized for publicizing the important identity of Phang Nga Province or local economic integration to produce souvenir products for generating household income. Result in 1) The create learning about the diversity of local cultures 2) Able to reduce the problem of plagiarism, product design, resulting in less piracy problem. This is to create jobs for local people and create local economies. As a result, tourists learn and be aware of the local identity. To promote the economy, which there are no such researches, scholars have studied Organized to create knowledge for the conservation of culture in Phang Nga

\section{Conclusion}

In conclusion, the findings from the analysis of qualitative showed that 1 . The "Chok" was a local southern plant with a growth period of about $15-20$ years 2. Mining miners have created wisdom by bringing "Chok" local plant in kind of palm that it was not invented to "Jungsui" Creative dance uniform because it was resistant to wear to prevent rain. By discovering the steps of the invention of the seven steps

1) Take the stems out of the barks.

2) Soak the barks in the salt water in order to make the barks thicker and stickier, and then completely sun-dry the barks.

3) Align the completely sun-dried barks on the same floor.

4) Cut the barks according to the plans.

5) Backstitch the barks with needles and threads.

6) Bind the barks with ropes in order to produce the durable rain coats.

7) Sew the prepared buttons on the rain coats.

Then, the production steps were used by the researcher as the guidelines for developing the rain coats for the creative dances.) 3. Bringing "Chok", a plant with no economic value Able to design costumes to promote tourism and promote sustainable tourism culture.

\section{References}

[1] Ministry of Agriculture and Cooperatives. "Geographical indications : The heart of community sustainability GI Market 2016." InEconomic base,9. Bangkok : Juthamas Building, 2017.

[2] Therdchai Choibamroong."The reform approach Thailand tourism." Tourism Authority of Thailand. <http://www.tatreviewmagazine.com/web/ menu-read-web-etatjournal/menu-

2014/menu-2014-oct-dec/615-42557reform>on October 62019.

[3] Yuttapong Tonpradoo"The development of Costumes in Baba Wedding Ceremony to Cabaret Shows." Doctoral Thesis, Mahasarakham University, 2017. 